\title{
More Evidence-Based Internet Self-Help Depression Websites Now Available
}

\section{Gordana Culjak $^{1}$, Peter Nicholls ${ }^{1}$, Rene Leveaux ${ }^{1}$ and Dr Nick Kowalenko ${ }^{2}$}

${ }^{1}$ Department of Information Systems, Faculty of Information Technology, University of Technology, Sydney. gordana@it.uts.edu.au; petern@it.uts.edu.au, rene@it.uts.edu.au

2 Department of Child and Adolescent Psychiatry, Royal North Shore Hospital, Sydney. nkowa@nsccahs.health.nsw.gov.au

Received 24 September 2006; received in revised form 21 December 2006; accepted 20 January 2007

\begin{abstract}
The aim of this research study is to evaluate the availability and classification of the types of currently available Internet self-help websites for depression. Its aim is to develop an understanding of what is available for people at risk of depression who would otherwise perhaps not seek help and to investigate whether such useful resources are on the increase. In Australia, depression is the top-ranked cause of nonfatal disability. Over $27 \%$ of young adults have a current mental disorder, with depression being the most prevalent (10.8\%). This paper investigates the availability and type of self-help websites that are available for people suffering from mild to moderate depression, as a step towards providing avenues for care for this population of sufferers. The most important finding of this study was that not only were there an increased number of websites available as self-help resources, but that over the three year period, there has been a statistically significant increase in the proportion of websites that are evidence-based. This is an important factor for sufferers of mild to moderate depression who are looking for access to online self-help resources.
\end{abstract}

Key words: Internet, Self-Help, Depression 


\section{Introduction}

The Internet is growing as an influential source of knowledge and information. The number of people using the Internet in 1995 was 2.3 million. In 1998, it had grown to 300 million, with an exponential growth pattern [14]. It has been found that only four in ten people with diagnosable behaviour or mental disorders ever seek help from a health professional [13]. Internet-based intervention has been suggested to be on the increase as a technological innovation [12]. It is therefore suggested that the Internet may help in providing access to a pathway to care for these people.

Globally, depression is the third major cause of disability, following cancer and heart disease [17]. It was found to be the top-ranking cause of non-fatal disease burden in Australia, causing $8 \%$ of the total years lost due to disability in 1996. Mental disorders overall were responsible for nearly $30 \%$ of the non-fatal disease burden, accounting for $3.7 \%$ of the total burden [16]. It is predicted that depression will be the second most common cause of global disability by 2020 and is currently a major risk factor for suicide and suicidal behaviour [17].

Depression is a major health issue in young people. The latest Australian Census of Population and Housing mental health and well-being profile [2] shows that the prevalence of mental disorder in the overall Australian population is highest $(27 \%)$ in young adults aged $18-24$ years. Australian youth have one of the highest suicide rates in the world. There are over 3.5 million $(3,636,900) 12-25$ year-olds in Australia, which is over one-fifth $(21 \%)$ of all Australians. The prevalence of depression in the young adult (20-24 year old) population is approximately $10 \%$, with depressive symptoms reported in $15-40 \%$ [2].

\subsection{Overview of Consequences}

Recent community services have confirmed that the vast majority of young people are unlikely to access services and get help from a counsellor, doctor or other professional service. Australian National Probability Sample Surveys [1] found that only $37 \%$ of people with current mental disorders had sought help through consultation. Similarly, it has been reported that only half of the subjects with panic disorder seek help for their attacks [11]. Long delays, such as one and a half years before seeking effective help are associated with poorer outcomes. Earlier intervention may enhance treatment outcomes. Specialist programs targeting this specific age group are needed. This is supported by Birleson, et al., (2001) [4], who suggests different programs for 0-17 year-olds and 18-25 year olds in order to be able to better assist them.

\section{Objectives}

The aim of this paper is two-fold. Firstly, it is to review what web services are available for people suffering from depression or related problems that may be seeking help or considering doing so. Secondly, it is to perform a comparative analysis of whether there has been any increase in the availability of such resources in recent years. Of particular interest is the availability of interactive and evidence-based self-help sites, where self-help means that the individual can use the website without the assistance of a third party. The aim is not to evaluate the quality of websites on depression as similar studies have been performed previously, suggesting poor information quality overall [3], [5], [7], [8], [15]. In this paper the authors have made the assumption that being evidence-based is one of (possibly) a number of characteristics of a quality website. This study considers that being evidence-based is a feature of interest in websites independent of any other aspect of quality that they may have. Depending on the availability and types of self-help sites available, this study will ideally serve as a basis for further studies in the quality of self-help sites in depression as opposed to general information sites. The authors also aim to investigate these trends, and based on their findings, make recommendations relating to directions and focus of future self-help websites.

\section{Research Methods}

For the web services review on the question of availability, Google was chosen as the main search engine as it is the most comprehensive [21] and ranked about equal to the top in quality [9]. The search criteria by Culjak (2003) [6] was "(self-help website) and (depression or psychological)" in the Google Internet Search Engine. They, as do the authors of this work, considered "depression" on its own being too broad for evaluating self-help websites. To ensure consistency between the two studies, the authors also used the same search criteria and search engine. The 2002 study yielded approximately 6,530 results, and this 2005 study yielded approximately 235,000 results. To ensure a most comprehensive study [20] and again to ensure consistency, the top-ranked 150 sites were explored. It has been previously reported [19] that few people search further than the first 10 links. Over 150 sites were searched in order to obtain the target 150 original, relevant and active sites. Where the search led to more than one occurrence of the site, all duplicate sites were replaced with the next in line until 150 original sites were obtained. A list of the websites examined may be obtained by contacting the authors. 
In the 2002 study, sites that required registration or payment prior to access were excluded in the final 150 most common hits, as registration or payment would be seen as a possible deterrent to web surfers of low mood. The same criteria was to be applied to the 2005 study, however the researchers found that no sites in the first 150 required registration or payment prior to access. On further investigation of an additional 30 sites, there was still no registration or payment required. The only indications of payment in the 180 sites (150 original +30 additional sites) occurred when visitors were offered opportunities to purchase books, subscriptions, services, etc, external to the site.

Sites were classified according to their primary focus and how helpful they were for people who might search the web when in need of immediate help for depression. In order to classify the types of self-help sites available, an overall impression rank score (1-3) was devised as an estimate of the usefulness and availability of direct help information and resources.

The sites ranked with a score of 1 were the more useful sites for immediately accessing direct help and constructive advice, referral, screening or treatment without having to traverse through a multitude of links to get to the information.

Sites with an overall score of 2 were sites that mainly held textual information in the form of definitions and links to other sites. Though useful, these were sites mainly consisting of links to other sites rather than those offering any benefits of their own; sites which did not add much to the existing resources available. Though most sites had a combination of features, rank 2 sites did not have as their primary purpose a direct link to advice, referral, screening or treatment. They were mainly informative sites and in some cases, were overwhelming in terms of information overload.

An overall impression ranking score of 3 was given to sites that seemed less useful both in terms of information and practical advice. A score of 3 also included sites that upon first impression seemed questionable in intent; this incorporated those sites that although may be of some use, seem to have a degree of author self-interest. This classification scale was also given to sites which were primarily an advertisement for a drug company or product rather than prioritizing the potential patient before profit.

The characteristics that were considered important to explore in terms of the classification of self-help websites for depression and related issues were as follows:

- The main purpose of the site:-

- Information - whether the main purpose of the site was to give information about the conditions or symptoms and links to further resources

- Advice - refers to whether the web site was primarily focused on giving direct advice

- $\quad$ Referrals - to practitioners or professional bodies for help [8]

- Treatment - any suggested modes

- Definitions - of depression or related issues and conditions

- Screening - in the form of a questionnaire that would help identify individuals suffering from or at risk of depression

- Target audience - Age groups were broken into those of different needs:-

- General

- Adolescence ( 13-17) - approximately school age

- Young Adults ( 18-24) - approximately University age

- Adults $(25+)$

- Elderly

- Professionals - 3 sites were mainly for professionals, rather than the general public.

- Interactive - engaging the user. This type of website could feature a screening questionnaire or a discussion group for example.

- $\quad$ Evidence-Based - links to journals, journals databases or well-known medical bodies

- Costs involved - for access to the site or for treatment

- Professional affiliation [18]

- Drug Company Involvement or Sponsorship [8] - characteristics that could potentially bias the site in terms of a vested interest.

The authors held several workshops amongst themselves to confirm and solidify the criteria to be used in the collection of data on each site visited. The authors were able to ensure consistency in the selection criteria used for the data collection between the two studies as one of the authors had been involved in both studies. At the conclusion of the data collection, to ensure consistency, a further cross comparison of a significant number of sites was carried out with authors assessing randomly selected sites which had originally been assessed by other authors. In this comparison, the few discrepancies noted were resolved by discussion between the authors.

In order to compare whether there was any statistical significance in the growth of directly helpful websites (those with a ranking of 1 under the criteria as described above), as well as other features of interest and whether there was a statistically significant difference in the main intention of the site, the authors compared the 2003 and the 2005 data 
using the Chi-Squared and Fisher's Exact Tests. All Chi-squared calculations used the S-Plus Statistical Package [10], the Fisher's Exact Test was calculated by hand, and all P-values are two-sided.

\section{Results}

This 2005 study found that, as in 2002, highly reliable (meaning they have some level of trustworthiness) and directly helpful (classified as Category 1) Internet self-help resources were not instantly accessible, nor readily available. The large proportion of the information is basic, low-level, repetitive or self-serving, with the occasional rare exception.

The main purposes of all of the web sites explored are shown in Table 1. They were broken down by the number of sites with these characteristics as their main, or one of their main intentions.

\begin{tabular}{|l|c|c|c|c|c|c|}
\hline Main Intention & $\begin{array}{c}\text { 2002 Study } \\
\text { Primary } \\
\text { Purpose } \\
\text { n/150 (\%) }\end{array}$ & $\begin{array}{c}\text { 2005 Study } \\
\text { Primary } \\
\text { Purpose } \\
\mathbf{n} / 150(\%)\end{array}$ & $\begin{array}{c}\text { Growth } \\
\mathbf{( + I - \% )}\end{array}$ & $\begin{array}{c}\text { 2002 Study } \\
\text { One of the } \\
\text { main } \\
\text { purposes } \\
\text { n/150 (\%) }\end{array}$ & $\begin{array}{c}\text { 2005 Study } \\
\text { One of the } \\
\text { main } \\
\text { purposes } \\
\text { n/150 (\%) }\end{array}$ & $\begin{array}{c}\text { Growth } \\
\mathbf{( +} I-\%)\end{array}$ \\
\hline Information & $145(96.5 \%)$ & $132(88.0 \%)$ & $-8.5 \%$ & $149(99.3 \%)$ & $143(95.3 \%)$ & $-4 \%$ \\
Advice & $2(1.3 \%)$ & $5(3.3 \%)$ & $+2 \%$ & $47(31.3 \%)$ & $55(36.7 \%)$ & $+5.4 \%$ \\
Referrals & $1(0.6 \%)$ & 0 & $-0.6 \%$ & $19(12.6 \%)$ & $24(16.0 \%)$ & $+3.4 \%$ \\
Treatment & 0 & $3(2.0 \%)$ & $+2 \%$ & $2(1.3 \%)$ & $21(14.0 \%)$ & $+12.7 \%$ \\
Definitions & $1(0.6 \%)$ & $8(5.3 \%)$ & $+4.7 \%$ & $35(23.3 \%)$ & $23(15.3 \%)$ & $-8 \%$ \\
Screening & $1(0.6 \%)$ & $2(1.3 \%)$ & $+0.7 \%$ & $38(25.3 \%)$ & $22(14.7 \%)$ & $-10.6 \%$ \\
\hline
\end{tabular}

Table 1: Comparison of Main Purpose Categories of Self-Help Websites Surveyed - 2002 and 2005

Most sites offered general information and advice (please refer to Table 1), with every 4 or 5 sites having reasonably accessible definitions and screening tools. From the analysis of websites, it was found that the main purpose of information/definitions $=97 \%$ of the 2002 websites and $93 \%$ of the 2005 websites. These results were not statistically significant ( $\mathrm{p}=6.86$, Fisher's Exact Test).

In both the 2002 and 2005 studies most sites were targeted at the general population with about 12\% (2002) and $17 \%$ (2005) focusing on young adults (Table 2). Also notable over the period was the increase in sites targeted at adults, rather than young adults, from $3 \%$ in 2002 to $9 \%$ in 2005 (Table 2). An important factor noted when exploring the sites was the target age group. The results are shown in Table 2.

\begin{tabular}{|l|c|c|c|}
\hline & $\begin{array}{c}\text { 2002 Study } \\
\mathbf{n}(\%)\end{array}$ & $\begin{array}{c}\text { 2005 Study } \\
\mathbf{n ~ ( \% )}\end{array}$ & $\begin{array}{c}\text { Growth } \\
\mathbf{( + I - \% )}\end{array}$ \\
\hline Target Audience & $132(88 \%)$ & $111(74.0 \%)$ & $-14 \%$ \\
General & $6(4 \%)$ & $1(0.7 \%)$ & $-3.3 \%$ \\
Adildren ( 1-12) & $10(6.6 \%)$ & $10(6.7 \%)$ & $+0.1 \%$ \\
Young Adults ( 21-24) & $19(12.6 \%)$ & $26(17.3 \%)$ & $+4.7 \%$ \\
Adults (25+) & $4(2.6 \%)$ & $13(8.7 \%)$ & $+6.1 \%$ \\
Elderly & 0 & $1(0.7 \%)$ & $+0.7 \%$ \\
\hline
\end{tabular}

Table 2: Comparison Self-help website target population groups by age - 2002 and 2005

As Table 2 shows, of the first 150 websites surveyed in 2005, there was an increase in the sites targeted at young adults by $4.7 \%$. This was not a statistically significant difference $\left(\chi^{2}=1.28 ; 1 d f, p=0.19\right)$. However, the results for adults in general (excluding the elderly) show a significant increase $\left(\chi^{2}=5.2 ; 1 \mathrm{df}, \mathrm{p}=0.0226\right)$. This runs somewhat counter to what was expected. If, as is generally believed, young adults are more at risk of depression than the adult population at large, one would expect the number of self-help websites targeted at young adults to grow more quickly than the number of sites which are targeted at adults over 25 years of age.

In 2002 two out of five websites showed some level of interactivity (Table 4), though this was limited to a chat room, test or quiz in most cases. By 2005 , only one in four sites showed a level of interactivity. A proportion of the sites that were searched (11\% in 2002 and $50 \%$ in 2005) were judged as evidence-based as they had links to journals, journals databases or well-known medical bodies. No sites, in either study, however, showed any official endorsement or recognizable quality standard by being linked to a web-trust assessment body, like DISCERN for instance [5].

The researchers classified the sites (see Table 3) according to their level of interactivity, their evidence based capacity, involvement with professional bodies or drug companies and the costs for access and treatment. 


\begin{tabular}{|l|c|c|c|}
\hline Other Features of Interest & $\begin{array}{c}\text { 2002 Study } \\
\mathbf{n}(\%)\end{array}$ & $\begin{array}{c}\text { 2005 Study } \\
\mathbf{n}(\%)\end{array}$ & $\begin{array}{c}\text { Growth } \\
\mathbf{( + ) ~ I - \% ) ~}\end{array}$ \\
\hline Interactive & $61(40.6 \%)$ & $36(24.0 \%)$ & $-16.6 \%$ \\
Evidence-Based & $17(11.3 \%)$ & $60(50.7 \%)$ & $+39.4 \%$ \\
Professional Affiliation & $71(47.3 \%)$ & $76(50.6 \%)$ & $+3.3 \%$ \\
Drug Company Involvement & $16(10.6 \%)$ & $16(10.7 \%)$ & $+0.1 \%$ \\
or Sponsorship & $2(1.3 \%)$ & $1(0.7 \%)$ & $-0.6 \%$ \\
Cost for Access & $3(2 \%)$ & $7(4.7 \%)$ & $+2.7 \%$ \\
Cost for Treatment & & \\
\hline
\end{tabular}

Table 3: Comparison of Classification of issues of importance for the potential web searcher

There was a notable increase in the amount of websites with evidence-based information in the 3 year interval (39.4\%). This was found to be statistically significant $\left(\chi^{2}=23.28351 \mathrm{df}, p<0.001\right)$.

Table 4 illustrates how available self-help sites were for obtaining direct help and constructive advice on depression without having to navigate a multitude of links. Thus, although there are Internet-based self-help programs available, most sites are information based and do not readily supply evidence-based resources.

\begin{tabular}{|l|c|c|c|}
\hline \multicolumn{1}{|c|}{ Overall Score } & $\begin{array}{c}\text { 2002 Study } \\
\mathbf{n ~ ( \% )}\end{array}$ & $\begin{array}{c}\mathbf{2 0 0 5} \text { Study } \\
\mathbf{n ~ ( \% )}\end{array}$ & $\begin{array}{c}\text { Growth } \\
\mathbf{( + I - \% )}\end{array}$ \\
\hline 1 - Direct help/advice & $22(14.6 \%)$ & $25(16.7 \%)$ & $+2.1 \%$ \\
2 - Information based & $80(53.3 \%)$ & $91(60.7 \%)$ & $+7.4 \%$ \\
3 - Irrelevant, or of relatively & $48(32 \%)$ & $34(22.7 \%)$ & $-9.3 \%$ \\
low credibility & & & \\
\hline
\end{tabular}

Table 4: Comparison of Overall Classification Rank of Self-Help Depression Sites

Sites awarded a Level 1 Classification Rank were relatively rare, especially on later hits, which confirmed that the sample of 150 sites was adequate to evaluate availability and classification. It typically included a combination of screening, referrals, information links and definitions. In both the 2002 study and the 2005 study, most sites (Table 4) held a lot of basic, low-level, repetitive textual information, definitions, links to many other sites and were classified in the Level 2 category. However, there was a trend towards increased usefulness in the intervening three years, the Level 1 and Level 2 numbers increasing at the expense of the number falling into the Level 3 Category.

In both the 2002 and 2005 studies there was a high proportion of Level 3 sites that may have had a link to a questionnaire, but the site itself did not feature this directly; and it would take relatively careful searching to find and access such information. This category included a lot of psychologists' sites - some which appeared quite low in value on first impression. Duplicates, irrelevant sites and dead links were excluded. There was a marginal increase in the number of sites with usefulness ranking of 1 . This increase was not statistically significant between 2002 and $2005\left(\chi^{2}=0.2271 ; 1 d f, p=0.63\right)$.

\section{Discussion}

This study found that highly reliable and directly helpful Internet self-help resources were not instantly accessible, nor readily available. This situation reflects very little change from the 2002 study. Apart from a few exceptional sites, a large proportion of the information was either basic, low-level, repetitive or self-serving, as opposed to valuable, credible, reliable and useful self-help Internet resources. The number of sites available has grown from 2002 to 2005 and there is some increase in the value to users in terms of the main purpose categories defined, particularly the percentage of sites that deal with treatment. There has also been a slight increase in the focus on young adults and other adults, perhaps representing an acceptance in the community that these age groups are most at risk. The reason for a relative decline in websites offering an interactive experience is not clear. The rise in the percentage of evidence-based sites seems to be linked to an increase in site specificity, that is, some sites deal specifically with post-natal depression, others with cancer-related depression, a finding not observed in the 2002 study. Overall, the researchers found a trend towards more sites in general, more focussed sites and some increase in value of sites. The most important finding of this study was that not only were there an increased number of websites available as self-help resources, but that over the three year period, there has been a statistically significant increase in the proportion of websites that are evidence-based. This is an important factor for sufferers of mild to moderate depression who are looking for access to online self-help resources, as the majority of the more severe cases are assumed to also need attention from a heath care professional.

However, usability remains a significant issue. To make facilitatory websites more available, helpful sites should use common keywords in prominent places (or other search engine techniques) so that articles are easily retrievable, 
and seen to be readily available. They should also contribute qualitative information and avoid limiting their content to hyperlinks, which are overwhelming in number and lead to repeatedly retrieving the same sites.

\section{Conclusion}

Depression is a significant health issue and a major cause of social disability. The Internet is growing as an influential source of knowledge and information, and a lot of people seek health information from the Internet. This review of the researchers' search results of 150 self-help websites on depression and related issues, revealed that there has been a significant growth in the number of self-help sites and that this growth is providing newer areas of specialisation and potential patient consultation. Though in the initial study there were a lot of Internet self-help sites available, the type of sites now available are providing more than a primarily information based, and are moving towards a rather more direct source of psychological help or advice. As many people who need professional help for mental disorders are not seeking help from a health care professional, self-help sites are a way for them to obtain help prior to primary care. Though there are Internet-based self-help programs available, specialist evidence-based interactive programs developed specifically for young people, especially at school age, are not yet available. Further research and development of online resources is required to fulfill this need. However, there appears to be a growth in the number of sites for young adults - and primarily via university counselling sites.

The increase of $6.1 \%$ in websites for adults (25+ years) and $4.7 \%$ in young adults ( $21-24$ years) indicates the rapid uptake of the Internet within this age group which is reflected in the availability of self-help websites and their presumed use as the over 25's are more Internet-competent. Even though this may seem like a strong claim to make over three years, in the context of the rapidly changing availability and functionality of the Internet and technology, it can be seen than this leads to greater access, awareness and presumed use. The rise in the percentage of evidence-based sites seems to be linked to an increase in site specificity, that is, some sites deal specifically with post-natal depression, others with cancer-related depression, a finding not observed in the 2002 study.

\section{Further Research}

This study has laid the basis for further research into the growth of self help websites for those suffering from depression and potentially determines projections that may be utilized to determine the validity and possible categorisation of self-help sites. In addition further research needs to be done into the use and effectiveness of selfhelp websites for people suffering from depression. It is envisaged that further research, yielding additional statistical information, would lay the foundation to extract additional findings. This research would be focussed on the increase in evidence-based sites and on sites for (25 years and over). For example, a comparative analysis of the reliability of evidence-based sites versus sites of anecdotal postings, such as the increasingly popular weblogs would be worthwhile.

\section{References}

[1] G. Andrews, C. Issakidis, and K. Carter, Shortfall in mental health service utilisation. British Journal of Psychiatry, no. 179, pp. 417-425, 2004.

[2] Australian Bureau of Statistics $(1997,1998)$ Australian Statistics Australian Government, Canberra. [Online]. Available: http://www.abs.gov.au/

[3] J. V. R. Belcher, and C. Holdcraft, Web-based information for depression: Helpful or hazardous? Journal of the American Psychiatric Nurses Association, vol. 7, no. 3, pp. 61-66, 2001

[4] P. Birleson, E. S. Luk, and C. Mileshkin, Better mental health services for young people: responsibility, partnerships and projects. Australian \& New Zealand Journal of Psychiatry, Vol 35, no. 1, pp. 36-44, 2001

[5] D. Charnock, and S. Shepperd, (1999, February). DISCERN on the Internet. Quality Criteria for Online consumer health information on treatment choices. [Online]. Available: He@lth Information on the Internet.

[6] G. Culjak, Cyber Psychiatry: A Review of Internet Self Help Sites for Depression and Related Problems, in Proceedings of Information Resources Management Association International Conference, Philadelphia, PA, 2003.

[7] G. Eysenbach, J. Powell, J., O. Kuss, and E. Sa, Empirical Studies Assessing the Quality of Health Information for Consumers on the World Wide Web. JAMA, no. 287, pp. 2691-2700, 2002.

[8] K. M. Griffiths, and H. Christensen, Quality of web based information on treatment of depression: cross sectional survey. British Medical Journal, vol. 321, no. 7275, pp. 1511-1515, 2000.

[9] D. Hawking, N. Craswell, P. Bailey, and K. Griffiths, (2000). Measuring search engine quality. Information Retrieval, 2000. In Press. [Online]. Available: http://citeseer.nj.nec.com/hawking01measuring.html

[10] Insightful Corporation, S-Plus 7.0.6. Seattle WA, 2005.

[11] D. A. Katerndahl, Panic attacks and panic disorder. [Review] [56 refs] Journal of Family Practice, vol 3, pp. 2758, 1996.

[12] D. J. Kavanagh and K.T. Mueser, The future of cognitive and behavioral therapies in the prevention and early management of psychosis: Opportunities and risks. Behavior Therapy, vol. 32, no. 4, pp. 693-724, 2001 
[13] R. C. Kessler, K. A. McGonagle, S. Zharo, C. B. Nelson, M. Hughes, S. Eshleman, H, Witten and K.S Kendler, Lifetime and 12-Month Prevelence of DSM-III-R Psychiatric Disorders in the United States: Results From the National Comorbidity Survey. Archives of General Psychiatry, vol. 51, no. 1, pp. 8-19, 1994.

[14] E. Lawrence, et al, Internet Commerce: Digital Models for Business, (2nd Edition) John Wiley, Brisbane, 2000.

[15] T.L. Lissman and J.K. Boehnlein, A critical review of Internet information about depression. Psychiatric Services, vol. 52, no. 8, pp. 1046-1050, 2001.

[16] C.D. Mathers, E.T... Vos, C.E. Stevenson and S.J. Begg, The Australian Burden of Disease Study: measuring the loss of health from diseases, injuries and risk factors. Medical Journal of Australia, vol. 172, no. 12, pp. 5926, 2000.

[17] C.J.L. Murray and A.D. Lopez, The global burden of disease: A comprehensive assessment of mortality and disability from diseases, injuries and risk factors in 1990 and projected to 2020. World Health Organisation, World Bank and Harvard School of Public Health, 1996.

[18] W. M. Silberg, G. D. Lundberg and R. R. Musacchio, Assessing, Controlling, and Assuring the Quality of Medical Information on the Internet: Caveant Lector et Viewor-Let the Reader and Viewer Beware. JAMA, Vol. 277 , no. 15, pp. 1244-1245, 1997.

[19] A. Spink, Web Search Trends Project: 1997-2005, paper presented at The Faculty of Information Technology Research Seminar, University of Technology, Sydney 25 May, 2005.

[20] U. Sekaran, Research Methods for Business. A Skill-Bulding Approach. (4th Ed.). USA: John Wiley and Sons, Inc, 2003. [21] D. Sullivan, (2001) The Search
http://www.searchenginewatch.com/reports/sizes.html

Engine

Report
[Online].

Available: 